\title{
Contenido mineral y proteína en germinados de quinua (Chenopodium quinoa Willd)
}

\author{
Mineral and protein content in quinoa sprouts (Chenopodium quinoa Willd) \\ Contenido mineral y proteína en germinados de quinua (Chenopodium quinoa Willd)
}

\author{
Rosa Huaraca Aparco \\ rhuaraca@unajma.edu.pe \\ https://orcid.org/0000-0003-4493-7754 \\ Universidad Nacional José María Arguedas, \\ Andahuaylas-Perú
}

\author{
Aydee Kari Ferro \\ akari@unamba.edu.pe \\ https://orcid.org/0000-0001-7598-7450 \\ Universidad Nacional Micaela Bastidas \\ de Apurímac-Perú
}

\author{
Fidelia Tapia Tadeo \\ ftapia@unajma.edu.pe \\ https://orcid.org/0000-0003-4892-941X \\ Universidad Nacional José María Arguedas, \\ Andahuaylas-Perú \\ Celinda Alvarez Arias \\ calvarez@unamba.edu.pe \\ https://orcid.org/0000-0003-1585-4001 \\ Universidad Nacional Micaela Bastidas \\ de Apurímac-Perú
}

\section{RESUMEN}

El consumo de cereales germinados tiene una potencial importancia en la alimentación con un amplio nivel de nutrientes, las vitaminas, minerales, proteínas, carbohidratos, ácidos grasos y enzimas. Los germinados son una alternativa alimenticia que contribuye con la disminución de la desnutrición en niños, madres gestantes y lactantes. El objetivo de la investigación fue determinar el contenido de proteína, hierro y calcio en tres variedades de quinua germinada (blanca Junín, negra ccollana y pasankalla) cultivas en la provincia de Andahuaylas. Se realizaron análisis de contenido de proteína, hierro y calcio mediante el método AOAC. los datos fueron analizados mediante ANOVA para comparar las variedades de quinua germinada. Los granos de quinua germinada analizadas presentan $12,19 \%$ de proteína (rango $11,86-12,48 \%$ ) con una media de $5,79 \mathrm{mg}$ de hierro/100g (rango $5,54-6,16)$, y 66,56 mg de calcio/100g. La variedad pasankalla mostro un mayor contenido de hierro en comparación con las variedades negra ccollana y blanca junin $(p<0.05)$. Todas las variedades presentan un contenido considerable de proteínas y calcio. Los resultados muestran información relevante con fines de obtención de formulaciones nutritivos para niños.

Palabras clave: Germinación; Hierro; Calcio; Quinua

\section{ABSTRACT}

The consumption of sprouted cereals has a potential importance in the diet due to its great contribution of nutrients, vitamins, minerals, proteins, carbohydrates, fatty acids and enzymes are more available. Sprouts are a food alternative that contribute to the reduction of malnutrition in children, pregnant and lactating mothers. The objective of the research was to determine the content of protein, iron, and calcium in three varieties of germinated quinoa (white Junín, black ccollana and pasakalla) grown in the province of Andahuaylas. An analysis of protein, iron and calcium content was performed using the AOAC method. the data were analyzed by ANOVA to compare the varieties of germinated quinoa. The germinated quinoa grains analyzed present $12.19 \%$ protein (range $11.86-12.48 \%$ ) with an average of $5.79 \mathrm{mg}$ of iron / 100g (range 5.54 - 6.16), and $66.56 \mathrm{mg}$ of calcium / 100g. The pasakalla variety showed a higher iron content compared to the black ccollana and white junin varieties $(p<0.05)$. All varieties have a considerable protein and calcium content. The results show relevant information for the purpose of obtaining nutritional formulations for children.

Key words: Germination; Iron; Calcium; Quinoa

\section{RESUMO}

O consumo de cereais germinados tem uma importância potencial na dieta alimentar devido ao seu grande aporte de nutrientes, vitaminas, minerais, proteínas, carboidratos, ácidos graxos e enzimas. Os brotos são uma alternativa alimentar que contribui para a redução da desnutrição em crianças, gestantes e lactantes. O objetivo da pesquisa foi determinar o conteúdo de proteína, ferro e cálcio em três variedades de quinua germinada (Junín branca, ccollana negra e pasakalla) cultivadas na província de Andahuaylas. Uma análise do conteúdo de proteína, ferro e cálcio foi realizada pelo método AOAC. Os dados foram analisados por ANOVA para comparar as variedades de quinoa germinada. Os grãos de quinoa germinados analisados apresentam $12,19 \%$ de proteína (intervalo 11,86 . $12,48 \%$ ) com média de $5,79 \mathrm{mg}$ de ferro / 100g (intervalo 5,54 - 6,16) e 66,56 mg de cálcio / 100g. A variedade pasakalla apresentou maior teor de ferro em comparação com as variedades ccollana preta e junina branca $(p<0,05)$. Todas as variedades têm um teor considerável de proteínas e cálcio. Os resultados mostram informações relevantes para a obtenção de formulações nutricionais infantis.

Palavras-chave: Germinação; Ferro; Cálcio; Quinua 


\section{INTRODUCCIÓN}

La ingesta inadecuada de minerales como el hierro y el calcio es un problema que afecta directamente la salud, especialmente en los niños y mujeres jóvenes. Se estima que hasta el $33 \%$ de la población mundial tiene deficiencia de hierro (1). De acuerdo a la encuesta nacional INEI, Perú, la prevalencia de anemia en la población de 6 a 35 meses de edad fue del 40,0\%, registrándose mayor incidencia en el área rural (48,4\%), que la urbana (36,7\%) (2). Este problema se extiende a madres gestantes y lactantes por la mala ingesta de alimento ricos en proteínas y de micronutrientes básicos como el hierro, calcio, ácido fólico y vitamina A. Frente a esta problemática existen alimentos que ayudan a mejor la alimentación a partir del consumo de productos ricos en nutrientes como los cereales.

La quinua es un grano andino que presenta un alto contenido en proteínas alrededor del $15 \%$. Presenta un excelente contenido de aminoácidos esenciales más amplio que en las leguminosas y otros cereales. Por ello, las proteínas de la quinua son capaces de complementar las proteínas de cereales o leguminosas (3)

La mayor parte de la quínua producida en el mundo contiene sobre $12 \%$ de proteína, en un rango promedio de 12 a $17 \mathrm{~g} / 100 \mathrm{~g}$ (4). Además, es reconocida como buena fuente de minerales, incluyendo potasio, calcio, magnesio, hierro, fósforo, zinc, manganeso y cobre $(5,6)$.

La germinación es un proceso biológico que se puede aplicar de manera fácil y económica para obtener nuevos productos alimenticios procesados biotecnológicamente. El consumo de productos germinados está aumentando porque numerosos estudios han documentado sus ventajas y beneficios para la salud $(7,8)$. Durante el proceso de germinación se activan enzimas hidrolíticas y también son las enzimas más novedosas sintetizadas que, junto con las sustancias de reserva en la semilla, se movilizan para ser utilizadas en el crecimiento inicial de la plántula (9). Los germinados son considerados como alimentos funcionales que facilitan su asimilación y aprovechamiento de nutrientes en el organismo $(10,11)$.

Por lo tanto, el objetivo del estudio es determinar el contenido de minerales (hierro y Calcio) en germinados de quinua de diferentes variedades.

\section{MATERIALES Y MÉTODOS}

Se utilizaron 10 kilogramos de semillas de quinua de las variedades blanca Junín, negra ccollana y pasankalla, las muestras fueron adquiridas de la Cooperativa Machupichu, con certificación orgánica, en la provincia de Andahuaylas $\left(13^{\circ} 42^{\prime} \mathrm{S} .73^{\circ} 24^{\prime} \mathrm{O}\right.$ a una altitud media de 2935 msnm), Perú. Con clima Cwd de acuerdo a Koppens con precipitaciones media anual alrededor de $1000 \mathrm{~mm} / \mathrm{año}$, humedad relativa media de $50 \%$ y temperatura de $-5^{\circ} \mathrm{C}$ a $21{ }^{\circ} \mathrm{C}$, con moderada incidencia de heladas. las cuales fueron almacenadas en bolsas de plástico hasta su posterior germinación. 


\section{Germinación de las semillas de quinua}

Las muestras se llevaron a un proceso de lavado manual con agua para eliminar las impurezas y saponinas. Una vez lavados y sin saponina se remojaron en agua (1:5) durante $6 \mathrm{~h}$ a temperatura ambiente. Se escurrió el agua y los granos húmedos se esparcieron en una capa delgada en bandejas de plástico cubiertas con filtros de papel e incubados en condiciones controladas: $22-24{ }^{\circ} \mathrm{C}$ y $80-90 \%$ de humedad relativa en oscuridad, con un tiempo de $48 \mathrm{~h}$ donde los germinados alcanzaron la misma longitud de radical ( 1 a $1,5 \mathrm{~cm}$ ). La capacidad germinativa se determinó según Hager (12), contando los granos germinados y expresándolo como porcentaje del número total de granos. Para determinar el porcentaje de germinación y grado de calidad se aplicó de acuerdo a la metodología descrita por Elizade A. (13). La semilla no germinada se utilizó como control. La germinación se llevó a cabo por tres replicas. Las harinas obtenidas de las muestras se envasaron en bolsas de polietileno y almacenados a temperatura ambiente hasta su uso posterior.

\section{Análisis de contenido proteico y minerales}

El porcentaje de proteína total se realizó por el método Kjeldahl, la mezcla resultante de la digestión se neutralizó con hidróxido de sodio y se destiló. El destilado se recogió en una solución de ácido bórico, para ser luego titulado y determinar el nitrógeno contenido en la muestra. El hierro total se analizó por método colorimétrico utilizando mediante el método del bipiridilo AOAC 2005 (14). El calcio total fue analizado por el método Raghuramulu (15).

\section{Análisis estadístico}

Los análisis muéstrales se realizaron por triplicado, para la evaluación estadística se utilizó un diseño completamente al azar (DCA); el análisis de varianza se trabajó con 0,05 de significancia; al encontrar diferencia significativa se procedió a realizar la prueba de comparaciones de medias de Fischer (LSD) a un nivel de $\alpha=0,05$. Los datos fueron procesados con la ayuda de los programas estadísticos de Centurion XVII y la hoja de cálculo Microsoft Excel 2016.

\section{RESULTADOS}

\section{Proteína}

En la Figura 1 se muestra el contenido proteico para cada variedad de germinado de quinua. El contenido de proteína en la quinua germinada variedad negra Ccollana presentó $12,48 \%$ mayor frente a las variedades pasankalla con 12,13 \% y blanca Junín con $11,86 \%$ con un pvalue $p<0,05$. Encontrándose un aumento en el contenido de proteínas en las dos variedades, excepto para la variedad blanca Junín que presentó un contenido bajo en proteínas. Estos contenidos están dentro de los reportados de 11,2 a 16,5 \% (16,17). El valor promedio de proteína en la quinua es cercano a lo señalado en las Tablas peruanas de composición de alimentos (18) para la quinua blanca de Junín donde se indica $12,2 \%$ de proteína; mientras que para la quinua blanca el valor es $13,3 \%$ 


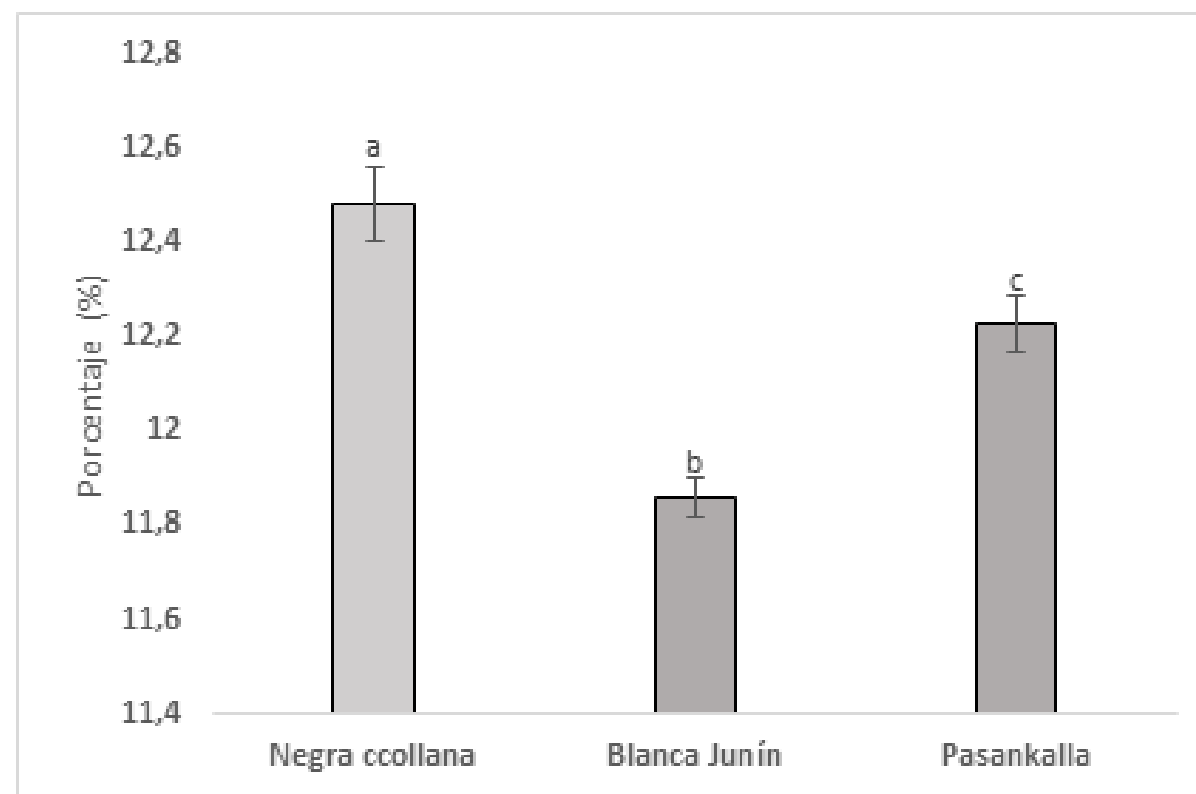

Figura 1. Contenido proteico de diferentes variedades de quinua. Diferentes letras minúsculas indican que hay una diferencia significativa, $(p<0,05)$.

\section{Hierro}

La Tabla 1 muestra el contenido de hierro de quinua sin germinar y germinado. Durante el proceso de germinación se observó un aumento del contenido de hierro en las variedades de quinua negra ccolana y pasankalla. De acuerdo a los reportes de Chaparro, et al., (19), se encontró una mayor concentración de hierro en el primer día de germinación. Los resultados encontrados demuestran que el contenido de hierro en las semillas de quinua mostro un aumento a medida que avanza el proceso de germinación. En comparación con otras investigaciones de Donangelo y col. (20). En su investigación sobre el efecto de la germinación en la composición química de leguminosas se encontró que la concentración de minerales presentaba diferencias con respecto al tiempo de germinación. El incremento de hierro pudo deberse a la posible disociación de su complejo con el ácido fitico $(21,22)$. Sin embargo, la variedad blanca junin mostro una disminución significativa frente a la semilla sin germinar. Una posible disminución en la germinación, puede deberse a la hidratación constante de las semillas según Sangronis y Manchado (23) y Donangelo y col (21) el constante remojo e hidratación es el factor de mayor influencia en las pérdidas de este mineral. De acuerdo a las investigaciones (24-27), quienes también afirman un incremento de la biodisponibilidad del hierro y otros minerales conzel proceso de la germinación. 
Tabla 1. Contenido de hierro $(\mathrm{mg} / 100 \mathrm{~g})$ en tres variedades de variedades de quinua germinada.

\begin{tabular}{lcccc}
\hline & \multicolumn{2}{c}{ Sin germinar } & \multicolumn{2}{c}{ Germinado } \\
\hline Negra ccollana & 5,12 & $\pm 0,05^{\mathrm{a}}$ & 5,67 & $\pm 0,05^{\mathrm{a}}$ \\
Blanca Junín & 4,54 & $\pm 0,02^{\mathrm{a}}$ & 5,54 & $\pm 0,02^{\mathrm{a}}$ \\
Pasankalla & 5,17 & $\pm 0,04 \mathrm{~b}$ & 6,16 & $\pm 0,04 \mathrm{~b}$ \\
\hline
\end{tabular}

Los valores seguidos de letra diferentes en la misma fila para las variedades de quinua son significativamente diferentes $(p<0,05)$.

\section{Calcio}

En la Tabla 2, se muestra el contenido de calcio para las semillas de quinua germinada y sin germinar. El proceso de la germinación en la variedad negra ccollana presento 71,23 $\mathrm{mg}$ de calcio/100g frente a la semilla no germinada, seguido de la variedad blanca Junín con $67 \mathrm{mg}$ de calcio/100. En comparación entre variedades la variedad pasankalla presento $61 \mathrm{mg}$ de calcio/100g. En el estudio se encontró un incremento significativo con el proceso de la germinación. En comparación con otras investigaciones se encontró registros de incremento de contenido de minerales $y$ vitaminas y proteínas en semillas, de acuerdo a Oloyo (27) se encontró un incremento de hierro y calcio en semillas de soya.

Muchos minerales presentes en semillas se encuentran con formación compleja de ácido fítico (28). El mayor contenido de calcio durante el proceso de germinación es consecuencia del hidrolisis de complejos de ácido fitico-calcio con la acción de fitasas durante la germinación de las semillas (20).

Tabla 2. Contenido de calcio $(\mathrm{mg} / 100 \mathrm{~g})$ en germinados de diferentes variedades de quinua.

\begin{tabular}{lcccc}
\hline & \multicolumn{2}{c}{ Sin germinar } & \multicolumn{2}{c}{ Germinado } \\
\hline Negra ccollana & 55,6 & $\pm 0,01^{\mathrm{a}}$ & 71,23 & $\pm 0,04 \mathrm{a}$ \\
Blanca Junín & 51,67 & $\pm 0,03^{\mathrm{a}}$ & 67,01 & $\pm 0,06 \mathrm{~b}$ \\
Pasankalla & 49,81 & $\pm 0,00 \mathrm{~b}$ & 61,45 & $\pm 0,02 \mathrm{c}$ \\
\hline
\end{tabular}

Los valores seguidos de letra diferentes en la misma fila para las variedades de quinua son significativamente diferentes $(p<0,05)$.

\section{CONCLUSIONES}

En el estudio se logró determinar el contenido proteína y minerales (hierro y calcio) en germinados de quinua de tres variedades (Negra ccollana, blanca junin y pasankalla). Las variedades negras ccollana y pasankalla mostraron un mayor incremento de hierro durante la germinación $(5,67$ y $6,66 \mathrm{mg} / 100 \mathrm{~g})$. El contenido de calcio más alto presentó la variedad negra ccollana $(71,23 \mathrm{mg} / 100 \mathrm{~g})$ frente a las demás variedades de estudio. En el estudio se encontró que la germinación presento un 
incremento de proteína y minerales en las semillas de quinua, siendo una alternativa de gran utilidad para prevenir la anemia.

\section{REFERENCIAS BIBLIOGRÁFICAS}

1. Zimmermann MB, y Hurrell RF. Deficiencia nutricional de hierro. The Lancet. 2007; 370:511 $-20$

2. Instituto Nacional de estadística e Informatica. 2020

3. Abugoch LE, Romero N, Tapia CA, Silva J, Rivera M. Study of some physicochemical and functional properties of quinoa (Chenopodium quinoa Willd) protein isolates. Journal of Agricultural and Food chemistry. 2008. 56(12): 4745-4750

4. Lutz M, Bascuñán-Godoy L. El resurgimiento de la quinua: un cultivo para la salud. En: Superalimentos y alimentos funcionales: una descripción general y su utilización para los alimentos procesados (V. Waisundara, M. Shiomi, Eds.) En Tech Open. 2017:37-54

5. Quinua: un cultivo ancestral para contribuir a la seguridad alimentaria mundial. 2011. Disponible en: http://www.fao.org/3/aq287s/ aq287s.pdf

6. Sánchez $H$, Solorza J, Mendez MG, Paredes LO, Bello PL. "Isolation and partial characterization of Okenia (Okenia hypogaea) starch". Método para determinar estabilidad al descongelamiento. Starch. 2002. 54: 193-197

7. Moongngarm A, Saetung N. Comparación de composiciones químicas y bioactivas compuestos de arroz en bruto germinado y arroz integral. Food Chem. 2010; 122:782-788.

8. Murugkar DA. Efecto de diferentes parámetros del proceso sobre la calidad de la leche de soja y tofu de soja germinada. J. Food Sci. Technol. 2015;52(5): 2886-2893

9. Bedón Gómez M, Nolasco Cárdenas O, Santa Cruz Carpio C, Gutiérrez Román A. Clasificación y caracterización de alfa amilasa de granos germinados de Chenopopdium quinoa (Quinua). J. Int. Sci. Reunirse. 2013;10(1): 51-57.
10. Snagronis E. y Machado C. Influence of germination an the nutrional quality of Plaseolus vulgaris and Cajanus cajan. Sci Dir: LWT. 2007; 40:116-120.

11. Davila MA, Angronis E. y Granito M. Leguminosas germinadpos o fermentadas: Alan-Archivos latinoamericanos de nutrición: Organo oficial de la sociedad latinoamericana de nutrición. 2003.53 (no.4):348-354.

12. Hager AS, Mäkinen, $O E$, Arendt, EK. Actividades amilolíticas y reserva de almidón movilización durante la germinación de la quinua. EUR. Food Res. Technol. 2014;239 (4):621-627.

13. Elizalde CA. Manual de prácticas: Tecnología de granos y semillas. Ppayan, Colombia: universidad del Cauca, Fcaultad de ciencias agropecuariasarias. S.f. 2014. 102 p. ISBN 9598-9475-58-2

14. AOAC (Association of Official Analytical Chemists). Official Methods of Analysis of the Association of Official Analytical Chemists. 18th ed. Gaithersburg, MD, USA. 2005.

15. Raghuramulu N, Nair M y Kalyansundaram SA. Manual for laboratory techniques, JamiOsmania, Hyderabad, India; National Institute of Nutrition, Indian Council for Medical Research. 1983.

16. Mota C. Santos M, Mauro R, Samman N, Matos AS, Torres D. Castanheira I. Protein content and amino acids profile of pseudocereals, Food Chemistry. 2016; 193:55-61

17. Navruz-Varli, N. Sanlier. Nutritional and health benefits of quinoa (Chenopodium quinoa Willd.), Journal of Cereal Science. 2016; 69:371-376

18. Reyes M, Gómez-Sánchez I, Espinoza C, Bravo F, Ganoza L. Tablas peruanas de composición de alimentos. Instituto Nacional de Salud. Octava edición. Lima, Perú. 2009. 64 $\mathrm{pp}$

19. Chaparro DC, Pismag P, Correa E, Quila V, Caicedo CA. Efecto de la germinación en el contenido de proteínas y la digestibilidad en semillas de amaranto, quinua, soja y grandul. 
Biotecnología en el Sector Agropecuario y Agroindustrial. 2011; 8(1):35-42

20. Donangelo M, Trugo N, y Col-Gum B. Effect of germination of legume seeds on chemical composition and on protein and energy utilization in rats. F. chem., 1995;53:23-7

21. Reihaneh Ahmadzadeh G, Prakash Jamuna. The impct of germination and dehulling on nutrients, antinutrientes, in vitro iron and calcium bioavailability of some legume seeds. Food Science and Technology. 2007;40(7):12921299

22. Hurrell richard y Egli Ines. Iron bioavailability and dietary refrence values. Am J Clin Nutr. 2010;91(5): 1461S-1467S

23. Gibson RS, Yeudall F, Drost N, Mtitimuni B, y Cullinan T. Dietary interventions to prevent zin deficiency. Am J of Clin nutria., 1998; 68

24. Hotz Christine and Gibson Rosalind S. Traditional Food-Processing and Preparation Practices to Enhance the Bioavailability of
Micronutrients in Plant-Based Diets American Society for Nutrition J. Nutri. 2007; 137:10971100

25. Lipski Elizabeth. Traditional Non-Western Diets. Nutr Clin Pract. 2010; 25(6):585-593

26. Srimapriya G, Usha A, y Chandra T. Changes in carbohydrate, free aminoacids, organic acids, phytate and $\mathrm{HCL}$ extractability of minerals during germination and fermentation of finger millet (Eleu-sine coracana). F. chem. 1997; 58:345-350

27. Duffus $C$, y Slaugther C. La semilla y sus usos. A.G.T. Editor. (México). 1985:131-1

28. Honke J, Kozlowska H, Vidal-Valverde C, Frías J, Górecki R. Cambios en las cantidades de fosfatos de inositol durante la maduración y germinación de semillas de leguminosas. Z Lebensm Unters Forsch FA 1998; 206:279-283 